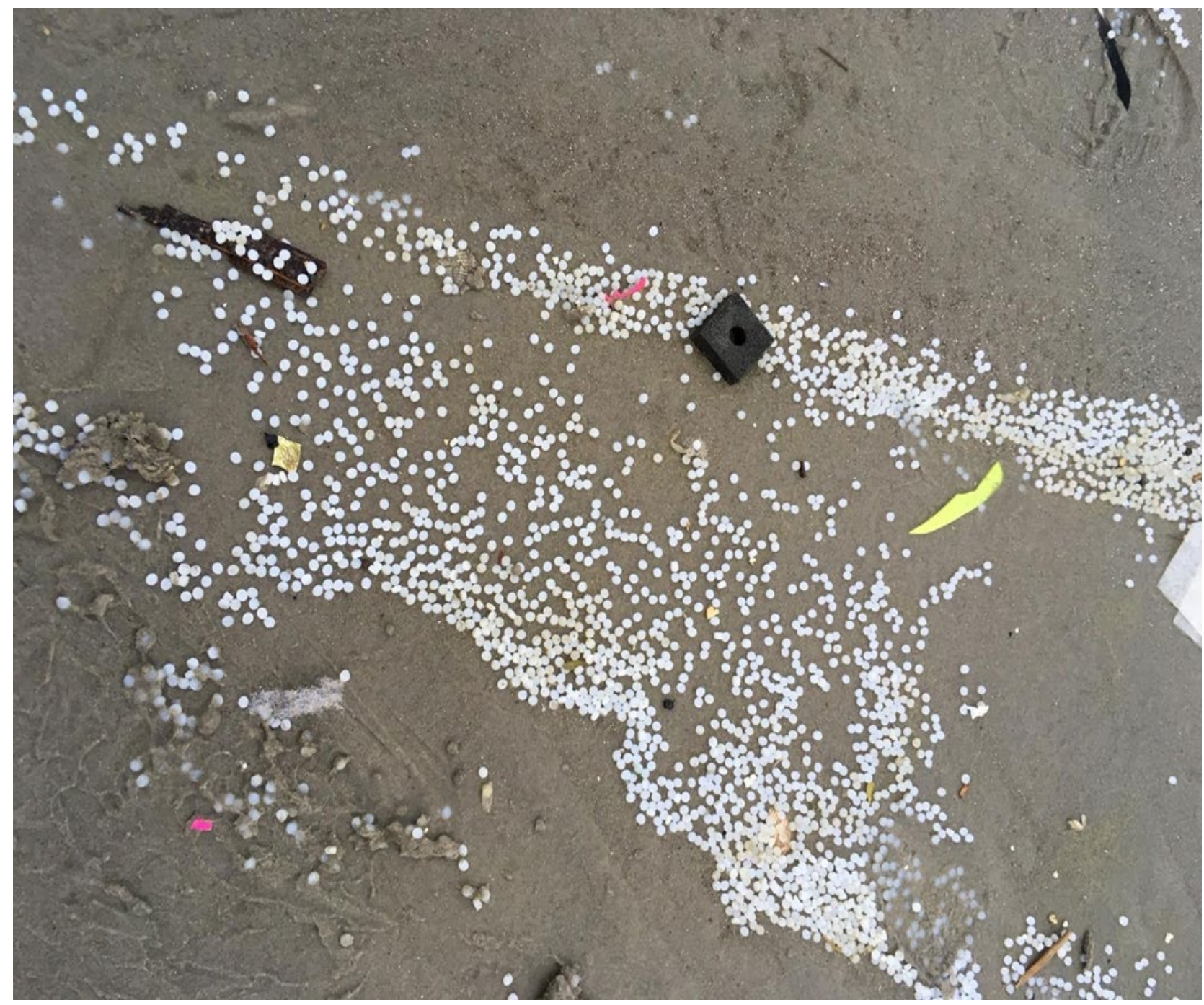

\title{
Inventory of aspects related to cleaning up microplastics after maritime incidents
}




\section{Inventory of aspects related to cleaning up microplastics after maritime incidents}


Keywords: coastal pollution, pellets, beach, salt marsh, dike

Client: $\quad$ Ministry of Infrastructure and Water Management

Attn.: Mareike Erfeling

Postbus 2232

$3500 \mathrm{GE}$, Utrecht

This report can be downloaded for free from https://doi.org/10.18174/560174

Wageningen Marine Research provides no printed copies of reports

Wageningen Marine Research is ISO 9001:2015 certified.

Photo cover: Plastic pellets on the tide mark of Schiermonnikoog beach in January 2019. Photo credits: Jan Willem Zwart, Natuurmonumenten

\section{(C) Wageningen Marine Research}

Wageningen Marine Research, an institute within the legal entity Stichting Wageningen Research (a foundation under Dutch private law) represented by

Drs.ir. M.T. van Manen, Director Operations

KvK nr. 09098104,

WMR BTW nr. NL 8113.83.696.B16.

Code BIC/SWIFT address: RABONL2U

IBAN code: NL 73 RABO 0373599285
Wageningen Marine Research accepts no liability for consequential damage, nor for damage resulting from applications of the results of work or other data obtained from Wageningen Marine Research. Client indemnifies Wageningen Marine Research from claims of third parties in connection with this application.

All rights reserved. No part of this publication may be reproduced and / or published, photocopied or used in any other way without the written permission of the publisher or author.

A_4_3_2 V32 (2021) 


\section{Contents}

$1 \quad$ Introduction $\quad 5$

1.1 Marine plastic litter and clean up strategy

1.2 Cooperation Coastal Pollution after Maritime Incidents $\quad 5$

1.3 Aim of the study $\quad 6$

1.4 Approach $\quad 6$

$2 \quad$ Background information $\quad 7$

$\begin{array}{lll}2.1 & \text { Container incidents with plastics } & 7\end{array}$

2.2 Effecten van plastic pellets op soorten en ecosystemen 8

$3 \quad$ Existing clearing methods $r$

3.1 Manual raking $\quad 10$

3.2 Manual sieving $\quad 10$

3.3 Manual vacuuming 11

3.4 Motorised vacuuming $\quad 12$

3.5 Traditional beach cleaners 14

$4 \quad$ Ecological impact of cleaning $r$

4.1 Beaches 15

4.2 Tidal flats $\quad 16$

4.3 Salt marshes $\quad 16$

$\begin{array}{llr}4.4 & \text { Solid dikes } & 18\end{array}$

$5 \quad$ Evaluation of clearing methods $\quad 19$

$6 \quad$ Clearing of plastics from water $r$

$7 \quad$ Conclusions and recommendations $r 22$

7.1 Most effective cleaning technique $\quad 22$

$\begin{array}{ll}7.2 & \text { Ecological impact of cleaning }\end{array}$

$\begin{array}{lll}7.3 & \text { Response and Cleaning strategy } & 22\end{array}$

$\begin{array}{lll}7.4 & \text { Cooperation } & 23\end{array}$

$\begin{array}{lll}7.5 & \text { Knowledge gaps } & 23\end{array}$

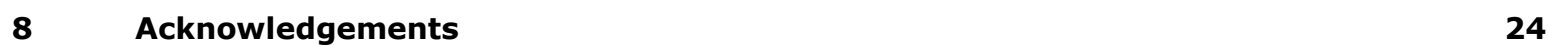

9 References $r 25$

$\begin{array}{lr}\text { Justification } & \mathbf{2 8}\end{array}$ 


\section{Summary}

The project Samenwerking Kustverontreiniging na Maritieme Incidenten (Cooperation Coastal Pollution after Maritime Incidents) explores how Rijkswaterstaat can better assist municipalities in cleaning up pollution that washes up on the coast after maritime incidents. In this context, an inventory has been made of methods that can be used to clean up the coastline from microplastics (particularly industrial pellets) that have ended up in the sea as a result of an incident.

Broadly speaking, there are three methods used to remove microplastics, namely raking, shovelling or vacuuming, after which a sieve may or may not be used to separate materials.

Shovelling or raking are suitable methods for removing plastics from soft sediments without vegetation, such as beaches and possibly tidal flats. On hard substrates, and on moist sand, the 'hoover' is an effective way to collect microplastics reasonably selectively, especially as long as the pellets are still on top of the sand. If the sand is dry, a combination with a sieving system is needed to separate the microplastics from the sand that is also collected. Vacuum cleaning can also be applied to overgrown areas, but as the overgrowth becomes denser, the efficiency with which microplastics are collected decreases. For the vacuum method to work effectively, it is also important to avoid vacuuming coarse (plant) material, as this can quickly clog the vacuum hose. All methods can be used on a small scale, manually, or on a large scale, motorised. Vacuum cleaning seems to be the most suitable method for cleaning up washed-up microplastics from the various substrates. There are a few companies that bring vacuum cleaning systems for the removal of microplastics to the market. These cleaning systems may or may not be equipped with systems that separate the waste, although separating microplastics and plant remains within a size fraction is not yet possible.

It is inevitable that organisms will be damaged or removed during clean-up operations. However, if these clean-up operations takes place in a limited area, quick recovery from the surrounding terrain is possible, provided that the structure of the subsurface has not been changed. Therefore, vacuuming is preferred to excavating and mowing.

To minimise the area that needs to be cleaned up, a fast response after an incident is important, as plastics can then be cleared while still concentrated in the flood mark. Ideally, an affected beach should be closed to the public so that plastics do not end up deeper in the sand through foot traffic or vehicles. For salt marshes, it is important to act quickly if the plastics are still low on the locations where the vegetation is less dense. Densely vegetated salt marshes (and silty tidal flats) are difficult to clean without substantial impact on the local system. Ideally, contamination of these areas is prevented by collecting the plastics from the water at an early stage, for example by using oil screens. If microplastics do end up in these areas, 'doing nothing' seems to be the best option, as the impact of the presence of plastic pellets on the ecosystem seems small. However, without specific research, this remains an assumption. It is possible that the ecological effects of plastic pellets are too subtle to be observed under field conditions, but from an ethical and aesthetic point of view, lost waste should always be cleaned up as much as possible.

For further development of knowledge on how best to react after an incident with microplastics, the exchange of knowledge and experience in this field should be promoted within the Netherlands and possibly Europe. If various prototypes of clean-up systems can be tested in this context, a better insight into their actual effectiveness can be obtained. This cooperation may also provide the market perspective that can encourage commercial parties to invest in improving the clean-up methods.

This report is a translation of the original report written in Dutch Inventarisatie aspecten rondom opruimen microplastics na maritieme incidenten (Wageningen University \& Research rapport 095/21). 


\section{Introduction}

\subsection{Marine plastic litter and clean up strategy}

The use of plastics has increased significantly since industrialisation, and in the year 2019, global production reached 368 million tonnes (PlasticsEurope, 2020). Some of this material ends up in the sea, and plastics in the environment are considered a serious problem worldwide (UNEP 2011). Animals may become entangled in macro plastics or ingest plastic particles, either accidentally or because they mistake them for food (Kühn \& Van Franeker, 2020). The effect of ingested plastic on natural populations is difficult to determine in the field and is therefore still subject to discussion. Laboratory studies do show negative effects, but often only at very high plastic concentrations under non-natural conditions. However, under more natural conditions in experimental ecosystems, such strong effects were not reproduced, and fish seemed to recognise the plastic granules that were applied as inedible (Foekema et al., 2021).

Large quantities of macro plastics can cover considerable areas on the seabed, coral reefs or along coasts, thereby restricting the transport of light and oxygen (see e.g. de Carvalho-Souza et al., 2018). In addition, there is economic damage. Plastic gets entangled in ships' propellers and polluted beaches are less frequently visited by tourists and need to be cleaned. A 2010 report calculated that Dutch and Belgian coastal municipalities spend an average of more than 10 million euros a year cleaning beaches (Mouat et al., 2010). Of course, this includes cleaning up natural materials that wash ashore, but it indicates that chronic beach pollution can cause substantial economic damage.

In addition to chronic contamination with plastics from various sources, substantial volumes of plastics also regularly end up in the sea via incidents, for example when container carriers lose part of their cargo in heavy weather, as happened to MSC Zoe in the north of the Wadden Sea in January 2019. It is estimated that between 2008 and 2019, an average of more than 1382 containers per year went overboard worldwide. In years with major container disasters, this number can rise to several thousand containers (WSC, 2020). It is estimated that between 300 and 10,500 tons of plastic are lost each year from these containers that went overboard (Galafassi et al., 2019). Such accidents occur worldwide, but clean-up actions are often taken locally, without much cooperation between countries or sharing of experience from previous events. Also on a scientific basis little has been published about such accidents and their aftermath.

\subsection{Cooperation Coastal Pollution after Maritime Incidents}

After the incident with MSC Zoe, the Ministry of Infrastructure and Water Management in the Netherlands was committed ${ }^{1}$ to explore how municipalities can better be assisted in cleaning up pollution that washes up on the coast after maritime incidents, and how the environmental impact of plastic pollution following maritime incidents can be limited in the future. For this reason, the government is investigating within the project 'Cooperation Coastal Pollution after Maritime Incidents' (Samenwerking Kustverontreiniging na Maritieme Incidenten) the scope for action for cleaning up microplastics following maritime incidents. Microplastics are defined as solid plastic balls/pellets of no more than $5 \mathrm{~mm}$ in size, which have ended up on the coast as a result of a maritime incident.

In general it is easier to clean up macro-pollutants/litter than micro-plastics. There are doubts about the feasibility of cleaning up microplastics in the coastal zone in an ecologically sound and costeffective way. Plastic particles spread quickly and are difficult to separate from organic material and

\footnotetext{
${ }^{1}$ Kamerstuk 27625, nr. 523 | https:// officielebekendmakingen.nl/kst-27625-523.html
} 
living organisms. More clarity is needed on the practical applicability and possible ecological effects of existing clean-up techniques.

Wageningen Marine Research (WMR) has therefore been asked by RWS to carry out an inventory of existing and innovative methods/technologies that can be used to clean up microplastics in the coastal zone. This report describes the results of this inventory.

\subsection{Aim of the study}

The aim of the study was to make an inventory of existing and innovative methods/technologies that can be used to clean up microplastics in the coastal zone. These were to be identified and assessed as far as possible against the following criteria:

- Ecological impact

- Indication of costs

- Effectiveness

- Technical and practical feasibility

- Developmental status (e.g. idea, prototype, commercially available)

In addition, an attempt was made to answer as many of the following supplementary questions as possible:

- What are the most relevant challenges and knowledge gaps for cleaning up microplastics on beaches (caused by maritime incidents)?

- What is still needed to develop a suitable technology?

- $\quad$ (How) can knowledge of the dispersion routes of microplastics from the sea to the coast be used to increase the efficiency of clean-up?

- $\quad$ Are there techniques to reduce/prevent the dispersion of microplastics on the coast so that clean-up can be carried out more efficiently?

- Is it possible to clean up floating microplastics before they are washed ashore? If so, how can this be done in combination with cleaning up on the coast?

- How does the cleaning up of microplastics relate to the simultaneous cleaning up of larger litter?

\subsection{Approach}

Part of the survey was carried out using information from international scientific and popular literature, and from various websites. In addition, telephone interviews were held with policymakers, companies, volunteers and NGOs who are or have been involved in one way or another in the clean-up of microplastics along the coastline in the Netherlands or elsewhere. It was decided not to quote interviewees personally but to summarise the results of these interviews. The names of the interviewees are included in the acknowledgements.

This report is a translation of the original report written in Dutch Inventarisatie aspecten rondom opruimen microplastics na maritieme incidenten (Foekema et al., 2021a). 


\section{Background information}

\subsection{Container incidents with plastics}

There is no global list of container losses at sea. The contents of lost containers also often remain unclear, and shipowners are not obliged to disclose the contents of a container, even after accidents. In 1990, the 'Hansa Carrier' in the North Pacific lost 21 containers with 61,000 Nike sports shoes. Those shoes washed up for years along the coastline of the United States and Canada. This container incident was the first in which plastic was used to track and better understand ocean currents (Ebbesmeyer et al., 1992). Later, in 1992, almost 30,000 plastic toys (plastic ducks, turtles, beavers and frogs) from containers that had fallen overboard were found in the Pacific Ocean. Some of these toys made impressive journeys. They were found years later in the US and Japan, but even ended up in Scotland, and on the American east coast (Ebbesmeyer \& Scigliano, 2007).

In 1997, the 'Tokyo Express' lost 62 containers in bad weather off the coast of Cornwall, containing, among other things, around 5 million Lego pieces, often in unusual, easily recognisable shapes, e.g. Lego dragons, pirates, squids, (diving) flippers, diving cylinders, and flowers. Years later, a container broke open and the Lego spread along the English coast, but Lego from that container was also found in the Netherlands (Figure 1).

In January 2014 containers went overboard in the middle of the North Atlantic, presumably from the ship 'Suez Canal Bridge' but that has never been confirmed. One notable item that washed ashore in large numbers were HP printer patterns. These were found back in Florida, but also in Troms $\varnothing$, Northern Norway. Most, however, washed up on the Irish and English coasts and along the European mainland coast. The distribution of this easily traceable material was used for scientific research. Flow patterns were investigated, but also the gradual degradation of plastic and related toxins and metals could be studied (Turner et al., 2021). The above cases illustrate that (micro)plastics lost at sea can travel a long way before stranding.

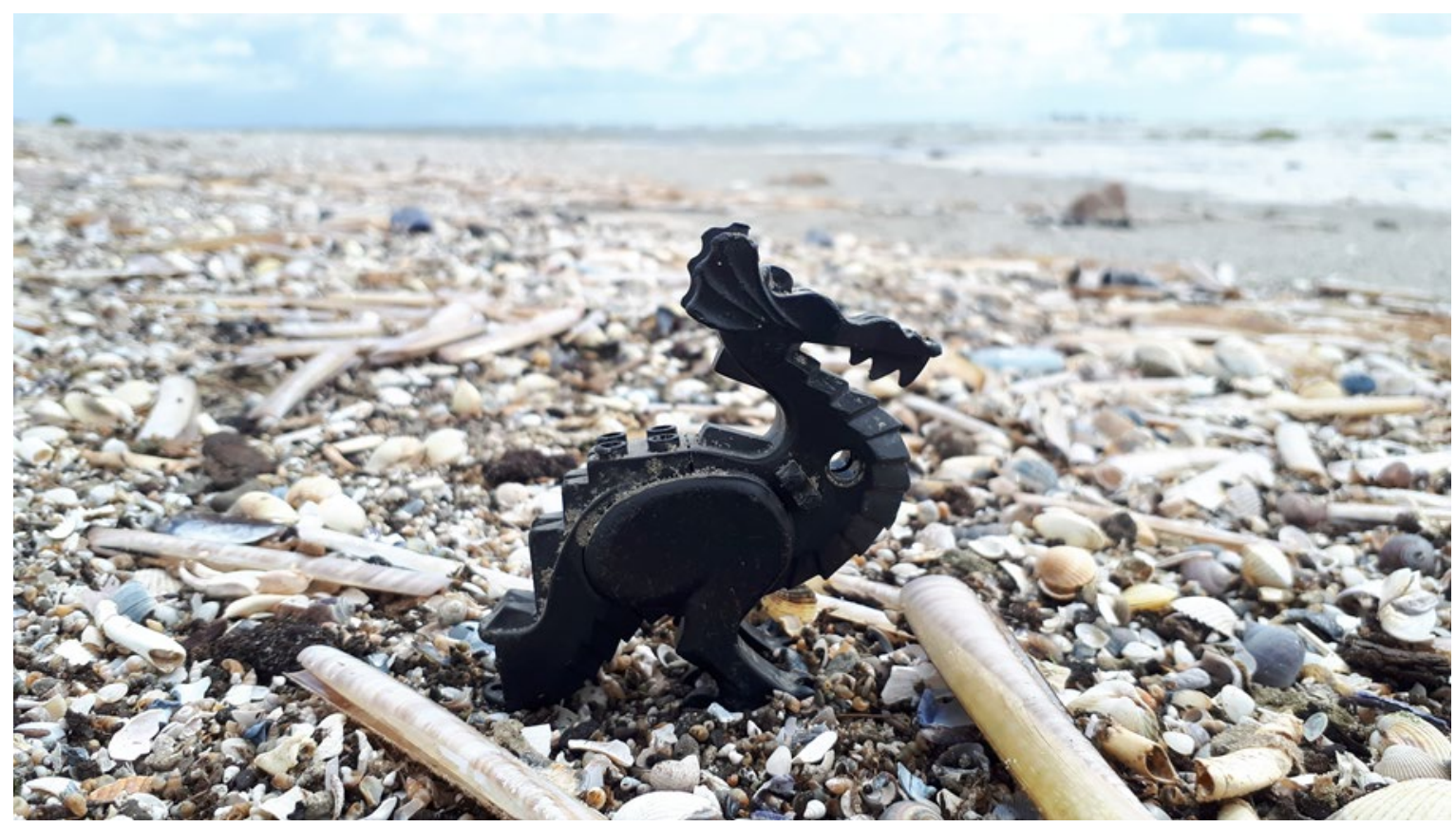

Figure 1

A Lego dragon, found on the Island Griend in the Dutch Wadden Sea in April 2020. The Tokyo Express lost about 34,000 of such dragons off the coast of Wales in 1997. Photo credits: Job ten Horn. 
When, as in the examples described above, it concerns specific identifiable products that can be related to an incident, it is possible to assign a responsible party. This is a lot more difficult when it comes to the loss of microplastics in the form of 'anonymous' semi-finished products (pellets) that are often produced and used worldwide.

In the North Sea, there have been two recent cases where many plastic pellets have gone overboard. As already indicated in the introduction, the 'MSC Zoe' lost 342 containers in a storm north of the eastern Dutch Wadden Islands in the first days of the year 2019. In the following months, 299 containers or parts thereof were salvaged (Rijkswaterstaat, 2021). In addition to many large plastic objects, it is estimated that $600 \mathrm{~kg}$ of polyethylene pellets were lost in this accident, partly loose but also partly in intact 25-kilogram bags that were found shortly after the incident on a salt marsh in province Groningen, the north eastern part of the Netherlands (Figure 2). Lose pellets washed up in large numbers on the beaches of the island Schiermonnikoog in the Wadden Sea (Philippart et al., 2019). At a legal level, these pellets could not be traced back to the MSC Zoe, as information about the exact content of the lost containers may not have been known, but in any case was not shared.

Over a year later, in February 2020, 13 tons of plastic pellets were lost by the container carrier 'MV Trans Carrier' in the central North Sea. The polypropylene pellets washed up in large quantities along the Danish, Norwegian and Swedish coasts. In Norway, 4.4 tons of the pellets could be recovered from the coastline with a lot of effort (Dolva, 2020).

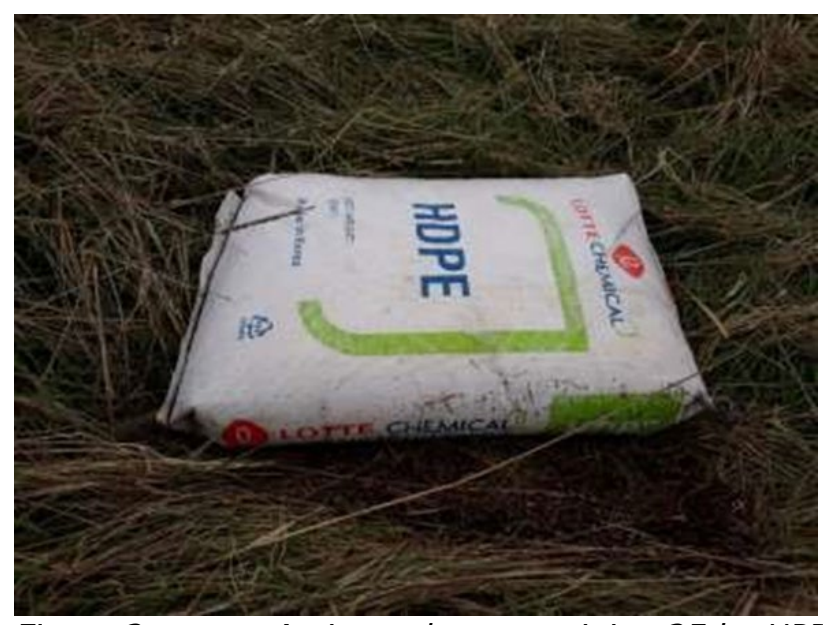

Figure 2 An intact bag containing $25 \mathrm{~kg}$ HPDE pellets as it was found on a salt marsh shortly after the incident with container carrier MSC Zoe. (Photo credits: Cor Sonneveld)

\subsection{Effecten van plastic pellets op soorten en ecosystemen}

Plastic pellets in the stomachs of marine animals were already observed as early as the 1960s, making them one of the earliest reports of plastics being ingested by animals. The first published observations were made between 1958 and 1978, when pellets were found in New Zealand seabirds (Harper \& Fowler, 1987). In the 1970s, they were also found in the stomachs of North Pacific seabirds (Day, 1980; Ogi, 1990). In 1971, pellets were also discovered in fish stomachs, first along the Atlantic coast (Carpenter, 1972), and in 1972 also in North Sea fish (Kartar 1976). Nowadays, more than 100 marine species have been reported with pellets in their stomachs, not only fish and seabirds, but also various shellfish, sea turtles and marine mammals (S. Kühn, unpublished data). In the Netherlands, northern fulmars (Fulmarus glacialis) in particular are known as plastic pellet eaters. From about 1980 , the amount of pellets in the stomachs of these birds has significantly decreased. Nowadays, on average 1.6 plastic pellets are found per fulmar's stomach (measuring period 2016-2020; Kühn et al., 2021). In the Netherlands, plastic pellets have also been found in other seabirds, such as gulls and 
divers (Van Franeker, 1983; Foekema et al., 2020), and in harbor porpoises (Van Franeker et al., 2018).

The pellets lost during the MSC Zoe incident were not found in the intestines of the different species studied, despite thorough examination. Only in a pellet from a lesser black-backed gull (Larus fuscus) on Schiermonnikoog pellets were found, that were very similar to the Zoe pellets (Foekema et al., 2021).

Pellets resembling the pellets that were lost by MV Trans Carrier were found in two of the 50 eider ducks (Somateria mollissima) that washed up dead on Norwegian beaches shortly after the MV Trans Carrier incident (Hanssen et al., 2020). No pellets were found in 633 fish examined during the same incident (Boitsov et al., 2020).

Little is known about effects of ingested pellets. In 1988, chickens were fed polyethylene (PE) pellets under experimental conditions. Chickens with pellets in their stomachs ate less and grew more slowly. According to the researchers, this was due to the plastic-limited volume in the animals' stomachs, which reduced the sense of hunger and the amount of food (Ryan 1988).

Effects on wild animals have never, to our knowledge, been established with any certainty.

Under semi-field conditions, with smaller plastic granules (diameter $0.7 \mathrm{~mm}$ as lost by MSC Zoe), a very slight decrease in the condition of juvenile sole was observed, which may indicate a slightly delayed intestinal passage in the presence of the plastic. Even at the highest dose of around 30 pellets per $\mathrm{cm}^{2}$, this difference remained so small that it could never be observed in a field situation. The small number of fish with plastic in the gastrointestinal tract and the low number of pellets per fish indicated that the fish recognised the pellets as inedible, and that pellets swallowed accidentally did not accumulate in the gastrointestinal tract (Foekema et al., 2019).

During the production of plastic pellets, at various steps chemicals can be added in order to give the plastic the desired colour, flexibility and other properties. These substances are also called additives. They are well 'baked' into the plastic matrix, but can also leak out of the material depending on the circumstances. Not all pellets contain such additives. In the pellets found after the incident with the MSC Zoe, no such substances could be detected (Foekema et al., 2021).

The pellets can also absorb contaminants from seawater, including the so-called 'Persistent Organic Pollutants' (POPs), such as PCBs (polychlorinated biphenyls) and brominated flame retardants. The amount of these substances in pellets can therefore exceed the concentration of the same substances in the surrounding seawater (Mato et al., 2001; Endo et al., 2005), as is also the case with the levels of these bioaccumulative substances in plants and animals present in the same water.

Both types of substances, the additives and POPs, can be absorbed by marine animals via plastics. However, the extent to which this contributes to total exposure is unclear. For POPs in particular, it is unlikely that ingested plastics play an important role as an exposure route in a natural situation. This is because these substances are also present to a significant extent in natural prey, from which they are more easily released upon passage through the gastrointestinal tract than from plastics (Koelmans et al., 2013a; 2013b). Recent research showed that chicks of wild seabirds that were fed plastic pellets to which additives (flame retardants and UV stabilisers) were added had significantly increased levels of these substances in their liver and fat (Tanaka et al., 2020). This result confirms the earlier assumption by the same researchers that in remote clean areas, microplastics can be a measurable source of additives for seabirds (Tanaka et al., 2018).

Little is also known about the effects of lost pellets on the ecosystem. In case of extremely large amounts, plastic can cover the sea floor and oxygen and light transport can be disrupted (de Carvalho-Souza et al., 2018). The amount of biomass underneath the plastic may then decrease (Green et al., 2015). To our knowledge, no deaths or ecological effects have been reported that could be undoubtedly linked to lost plastic pellets. 


\section{Existing clearing methods}

\section{$3.1 \quad$ Manual raking}

Initially, a rake was designed to better monitor the presence of larger microplastics on beaches. In the design by Haseler et al. (2018, 2019, 2020), a large hemispherical sieve is attached to a stick that can then be pulled through the sand (Figure 3). Sieves of different sizes can be installed. The standard sieve is half a metre wide, has a mesh size of $2 \mathrm{~mm}$ and, according to the authors, screens the top 3$5 \mathrm{~cm}$ of the sand. With these dimensions, pellets can be collected reliably. This method is suitable for dry sand, on and next to the tide line. When the sieve is full, natural objects and plastic or waste must be sorted manually. During an experiment in which small plastic pieces were distributed on the test surface, more than $50 \%$ of the plastics could be found (Haseler et al., 2020). This worked 30 times better than finding plastic by eye alone. To clean a $100 \mathrm{~m}^{2}$ stretch of beach, 2 persons needed about 5 hours. Using the rake was more efficient than scooping up the top layer of sand to a portable sieve (Haseler et al., 2020). The costs for the object itself are low, the authors estimate between 150 and 250 Euro. One does not need much experience to handle the rake and separate plastics from natural objects. The method is less suitable for wet sand and the rake does not work at all on stone surfaces (Haseler et al., 2019).
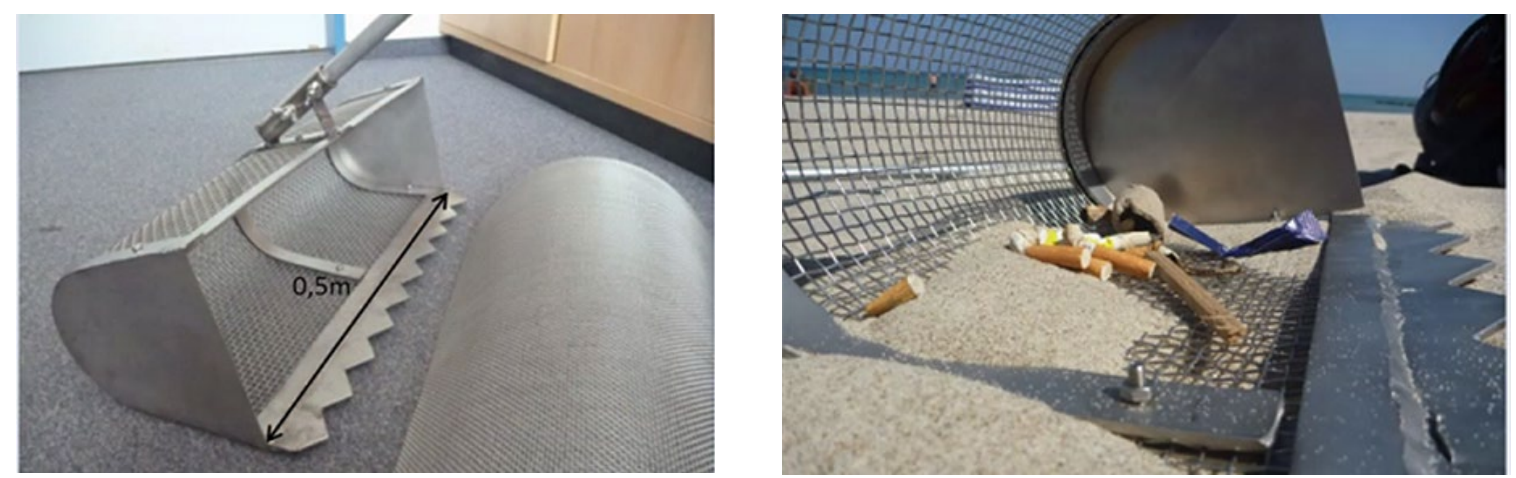

Figure 3 The rake, designed by Haseler and colleagues. The mesh size in the pictures is 5 $\mathrm{mm}$, but can easily be changed to also collect pellets reliably.

\subsection{Manual sieving}

Worldwide, volunteers are committed to remove microplastics from the environment. On beaches, this is usually done by scooping up the top layer of sand and then manually sieving it.

Volunteers from the Dutch 'Bende van Strand' have converted a handcart to carry two sieves, one coarse and one fine, placed one above the other (Figure 4). These sieves are vibrated by an electric motor, so that the material scooped in is divided into three fractions. The coarse material remains on the upper sieve, which includes macroplastics and plant material. The finer material, including plastic pellets, collects on the second sieve. The smallest fraction, which mainly consists of sand, sinks through this sieve and is not collected. As an experiment, this sieve system was also used in combination with a suction hose so that manual shovelling was no longer necessary. According to the builders, good results were achieved. They therefore see possibilities for scaling up the system. Separation of the material collected on the sieves into waste (plastics) and natural material is done manually. 

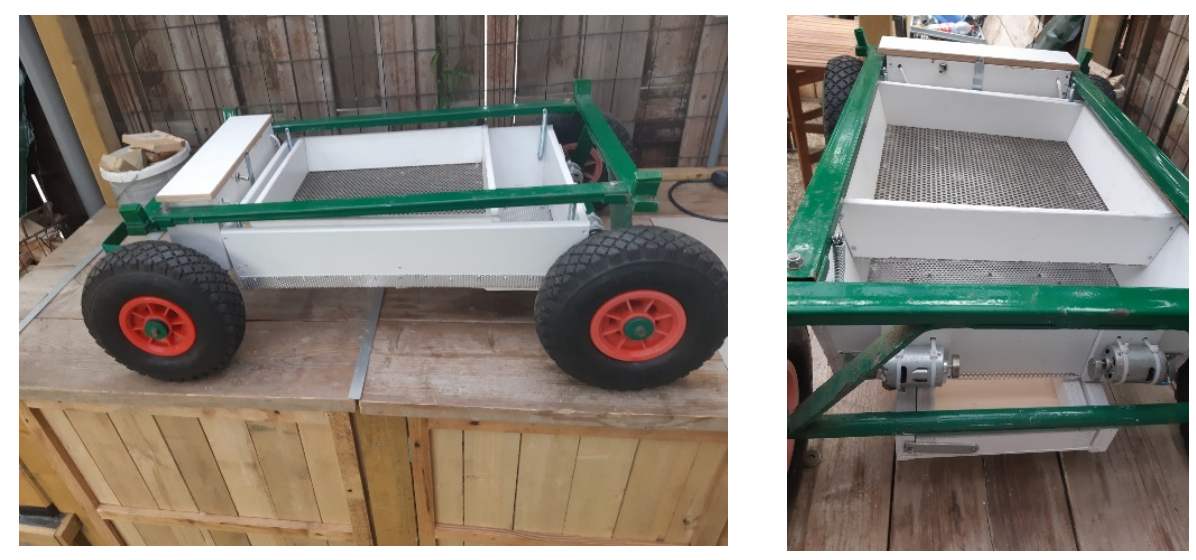

Figure 4 The screen cart of the 'Bende van Strand' (https://www.debendevanhetstrand.nl/)

The UK-based group Nurdle.org markets a drum screen for this purpose called the 'Microplastic Drum'. It can be operated manually and enables sand to be sieved with less effort (Figure 5). The group itself uses this drum mainly to create awareness among the public about microplastic pollution.

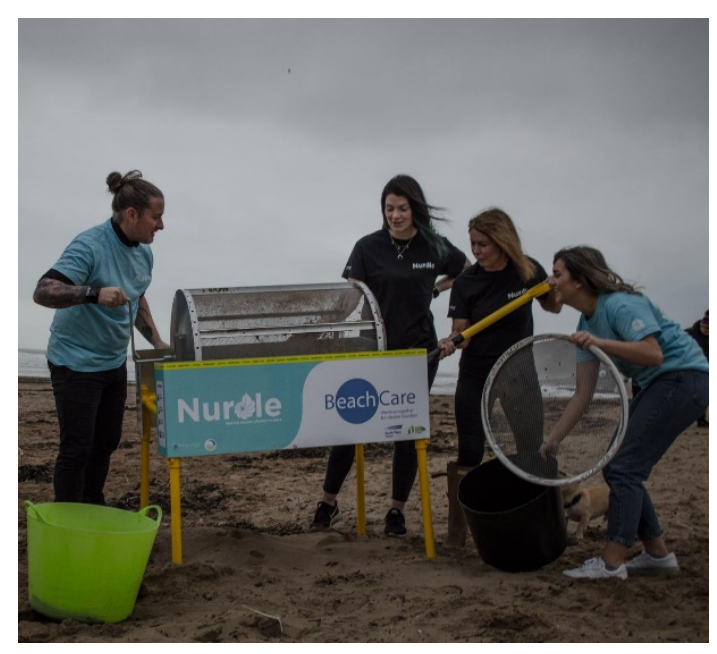

Figure 5 The Microplastic Drum Sieve of Nurdle (https://nurdle.org.uk/microplastictrommel)

\subsection{Manual vacuuming}

Manual hoovers (e.g. leaf vacuums) can be used in different areas to collect microplastics. Unlike motorised vehicles, manual hoovers are flexible and can also be used on terrain where large machines can cause a lot of damage. In the container incident of the 'MV Trans Carrier', such hoovers were used successfully (Dolva et al., 2020). The authors give a number of conclusions and recommendations. The backpack model is the most practical model, where the hoover is carried on the back with a container. The container can be improved by adding a sieve to the bottom, which immediately traps fine material such as sand. The systems equipped with fuel combustion engine lasts have a long running time and are easy to use in the field. Systems with batteries, have a somewhat shorter running time but are more durable and cause less noise. With appliances that require a battery, it is necessary to have sufficient spare batteries available. In Norway, manual hoovers were especially 
handy at cleaning areas between stones, where large machines cannot reach. Beaches with dry, fine sand were found to be less suitable, as the collection bins then quickly became filled with sand.

Little is known about the exact efficiency of manual hoovers, but Dolva et al. (2020) recommend that it is more efficient to use two people per hoover. While one person is vacuuming, the other can, if necessary, sort the contents of the collection box or replace batteries.

\subsection{Motorised vacuuming}

For the professional clean-up of microplastics along coastlines, motorised vehicles equipped with 'hoovers' are often used. Some of the available motorised vacuum cleaners are described below.

In the spring of 2019, the company BDS initially used a suction flail mower to collect washed-up plastic pellets from the edge of the dunes at Schiermonnikoog. The vegetation was cut off and collected in a container via a vacuum system. It is estimated that $80 \%$ of the pellets were removed in this way, but it also produced a lot of plant material that was difficult to separate from the plastics. Sand was separated on the basis of buoyancy. Later, the flail mower was removed and only the vacuum suction system was used to suck up material, without mowing (Figure 6). According to observers, the suction system was quite efficient in undisturbed areas, but the pellets were much more difficult to suck up when they had been driven deeper into the sand by foot or vehicles. Clearing along the high tide line was limited by the wheel pressure of the vehicle, so that clearing was only possible at very low tide. The clean-up operation on Schiermonnikoog lasted approximately 2 months and was terminated due to the start of the breeding season.

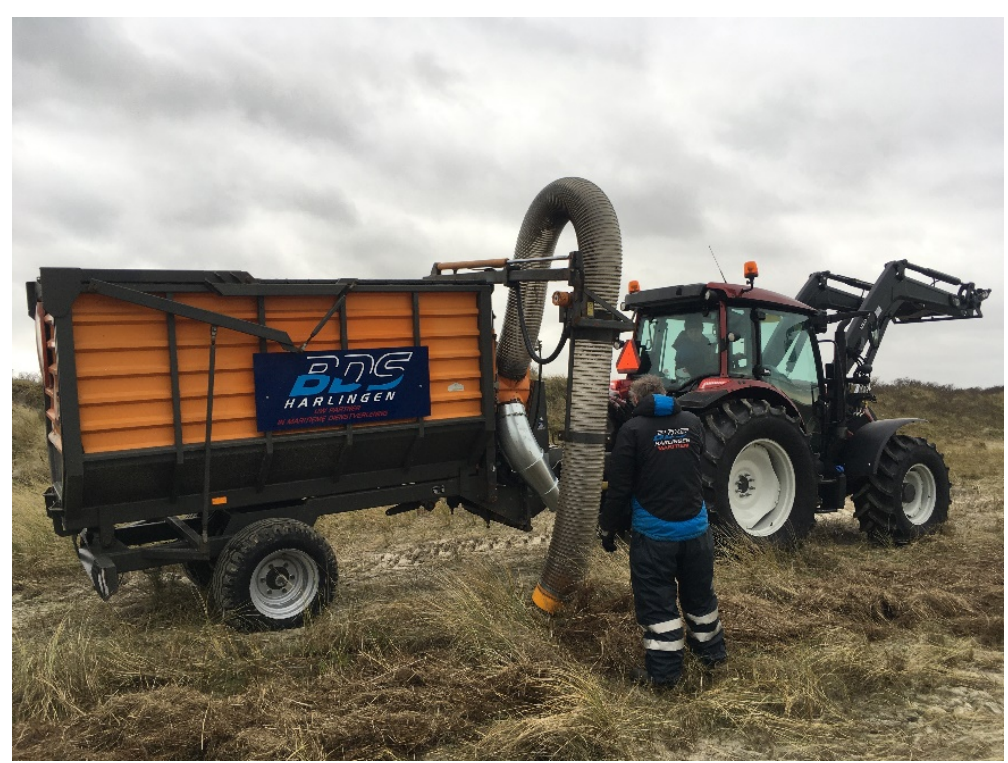

Figure 6 The BDS company at work on Schiermonnikoog (Photo by Natuurmonumenten)

For clean-up activities in the port of Rotterdam, the firm HEBO Maritime Service used a vacuum system placed on a ship to vacuum up microplastics from the banks of dykes (Figure 7). According to HEBO's estimate, in a three-day period 200-400 $\mathrm{m}^{2}$ of surface area was cleaned. To prevent the suction mouth from blocking, coarse material had to be removed in advance. The collected material is not yet separated. There are ideas on how this can be done, but due to limited market prospects, no investments have been made in this area (yet). 


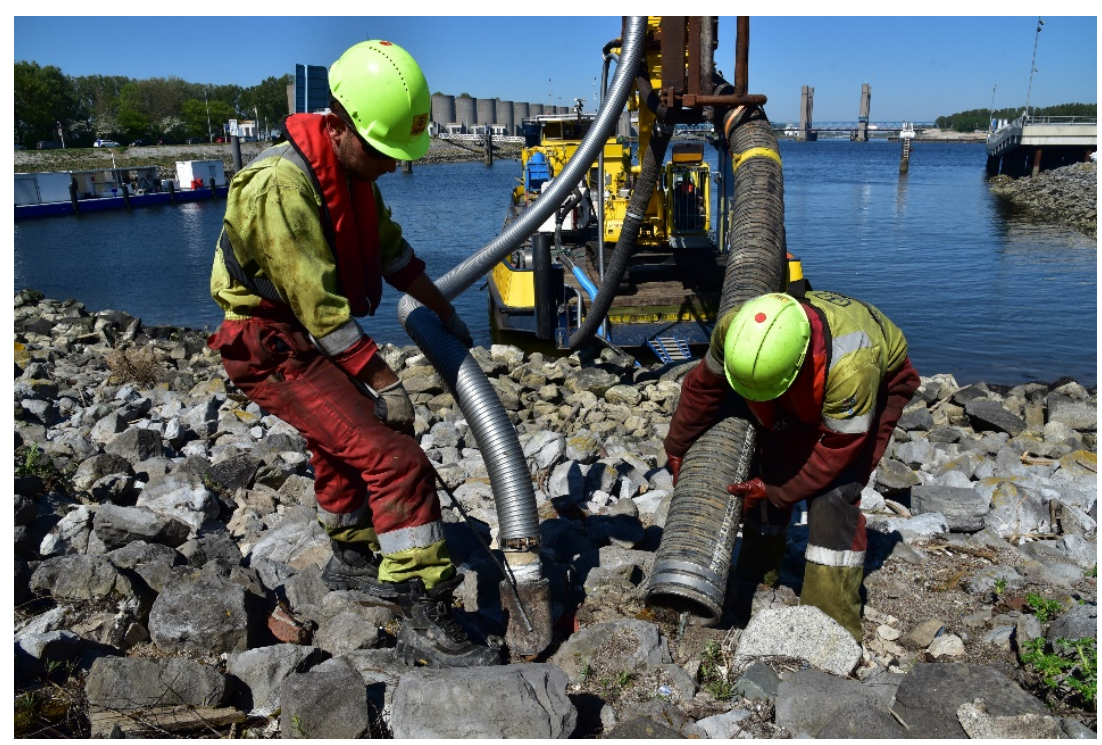

Figure $7 \quad H E B O$ Maritiemservice BV removes microplastics in the port of Rotterdam using a vacuum system on a boat (Photo: HEBO Maritiemservice BV; https://www. hebomaritiemservice. $n \mathrm{l} /$ ).

After winning a competition organised by the port of Antwerp, the company Envisan (part of the Jan de Nul Group) developed the prototype of the Zero-O-Plastic, a tracked vehicle (wheel pressure $200 \mathrm{~g} / \mathrm{cm}^{2}$ ) equipped with a suction hose and a collection bucket (Figure 8 ). The system has been successfully used on hard banks (dike embankments) and on salt marshes with not too much vegetation. The effectiveness of the system diminished with rougher vegetation and in humid conditions when the pellets stick to the surface. Depending on the substrate, an area of between 0.2 and $1 \mathrm{~m}^{2}$ could be cleaned per minute. The vacuumed material is currently incinerated in its entirety, because separation of plastics and organic material is difficult. The Zero-O-Plastic has not been tested on the beach because it is expected that too much sand would be sucked up. The operational costs of cleaning with this machine are approximately $€ 300 /$ hour.

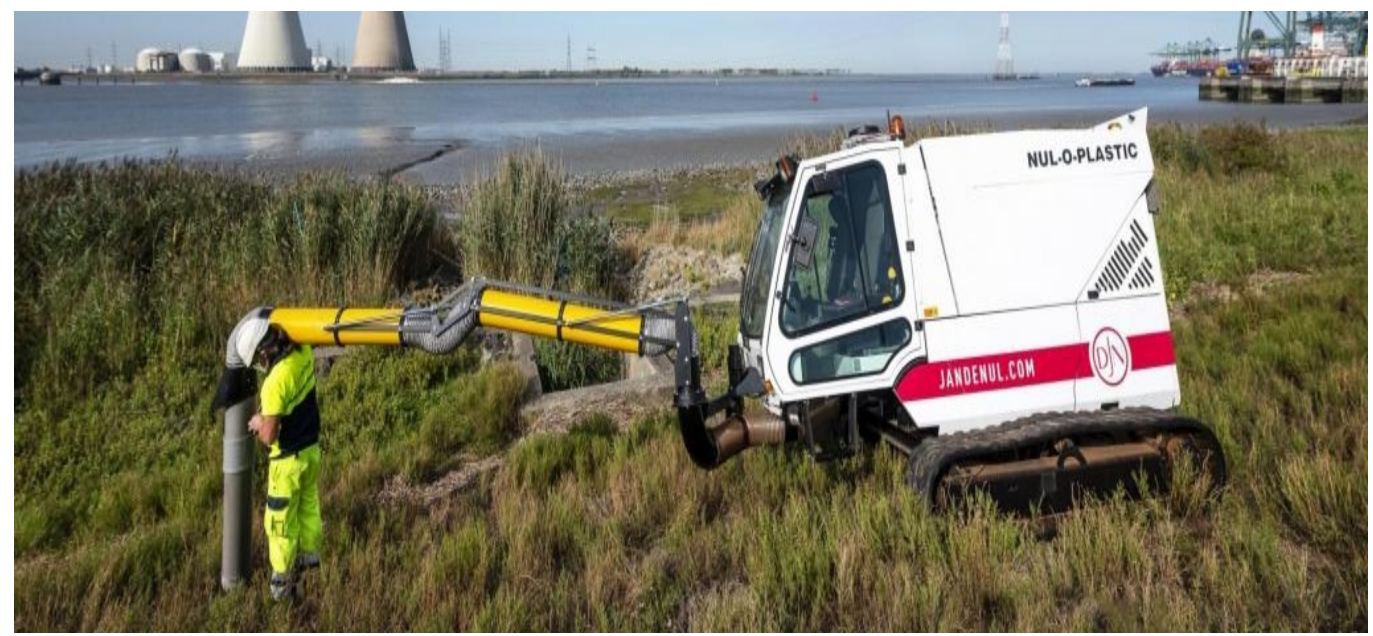

Figure 8 The Nul-O-Plastic of Envisan. (photo: https://www.jandenul.com)

Outside the Netherlands, several cleaning systems based on the hoover principle have also been developed, some of which are or will be commercially available. The 'Microplastic machine' by Nurdle (UK; https://nurdle.org.uk/microplastic-machine/) is built on a cart that can be coupled behind a small vehicle (e.g. a quad) (Figure 9). The prototype system is currently being tested for effectiveness on ecological impact in collaboration with the University of Southampton and is expected to be commercially available around April 2022, at an expected cost of around $€ 15,000$. The Microplastic machine can be optionally equipped with a wide suction nozzle for use on flat beaches or with a 7metre-long suction hose that can be manipulated by hand. This can be helpful if the area to be 
cleaned is difficult to access or has a lot of vegetation and/or height differences. The collected material is separated over 3 vibrating screens, of which the mesh size can be adjusted to the situation. Each sieve fraction is collected in a separate 'waste bag', so that fractions containing little or no plastics can be returned to the research area. Meanwhile, Nurdle is working on a method to separate plastics from plant material of the same size, but this system will not be commercially available by April 2022.

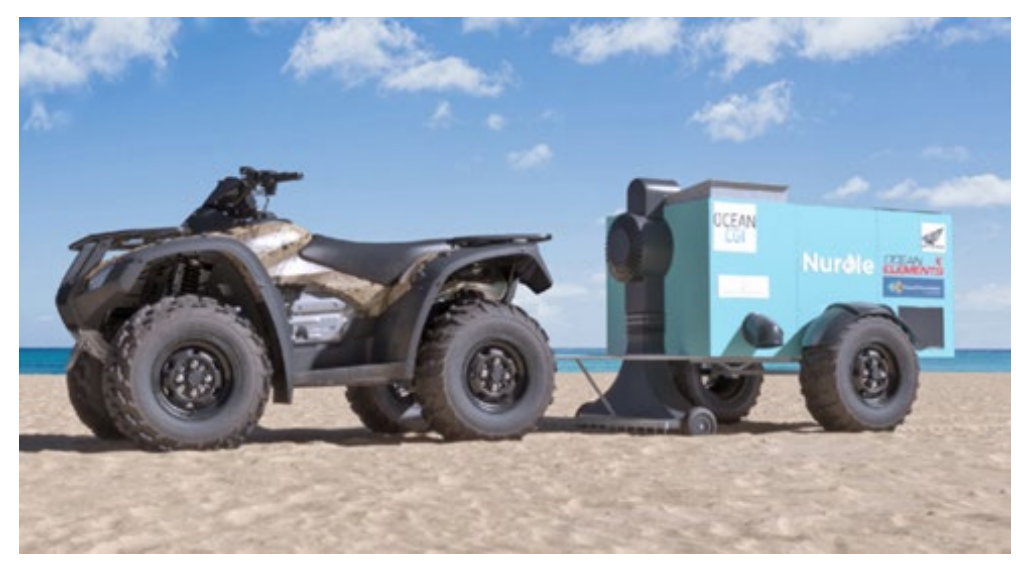

Figure 9 The Microplastic machine of Nurdle.org, here equipped with a suction nozzle for use on flat beaches (https://nurdle.org.uk/microplastic-machine/)

In Canada, the company Hoola One (https://hoolaone.com/home/) developed a motorised vacuum system called HO1, which uses water to separate materials based on differences in buoyancy. The HO1 therefore requires a continuous supply of water. The water separation method is effective when working with sticky (wet) sediment and to separate heavier material such as shells, sand and stones from plastics, but it cannot separate (plant) material with the same buoyancy as plastics. The company does say it is working on an innovative technology called FiltrUs, which they expect to enable full separation of organic material from plastics. This technology will however not be available before the year 2024. The HO1 would be able to clean up an area of about $60 \mathrm{~m}^{2}$ per hour. It is expected to be brought to the market from 2023 at an estimated price of around US\$100,000. The same company has also recently developed the $\mathrm{HO} 2$, in which the collected material is separated using sieves. This does not require a continuous supply of water. According to estimates, the HO2 could clean up an area of around $200 \mathrm{~m}^{2} /$ hour on a sandy beach. Like all sieving systems, it works best with dry, loose sand. The HO2 will be commercially available from 2022 at an estimated price of around US\$ 45,000.

\subsection{Traditional beach cleaners}

On many tourist beaches, beach cleaners are used to efficiently remove coarse litter and washed-up material such as seaweed. These beach cleaners work according to a raking or sieving mechanism that is usually driven behind a tractor over the beach (http://www.beachcleaner.com/beach cleanermethods.html). The rake mechanism is only suitable for collecting coarse material that is picked up by the rake, and is therefore not suitable for cleaning up microplastics.

The beach cleaners, which are equipped with a sieve mechanism, scrape the top layer of sand and 'shake it out' in a sieve. If the sieve diameter is less than $5 \mathrm{~mm}$, this method should also be able to collect microplastics.

Such sieve systems are mainly used on smaller beach cleaners designed for (private) beaches of limited size. These cleaners are usually manually controlled, but a remote-controlled robot, the BeBot, has been developed in the USA. The BeBot scoops up sand to a depth of $10 \mathrm{~cm}$, which is then sieved on a shaker sieve with a standard mesh size of $1 \mathrm{~cm}^{2}$. The system seems effective in collecting cigarette filters from dry loose sand that quickly sinks through the sieve (https://www.designboom.com/technology/bebot-robot-tiny-plastic-waste-clean-beaches-4ocen-0802-2021/). However, like any 'dry' sieving system, the efficiency will quickly be reduced by sticky wet sand, especially when working with the smaller sieve diameters that are needed to collect microplastics. 


\section{$4 \quad$ Ecological impact of cleaning}

\subsection{Beaches}

Shortly after an incident near the coast, microplastics washed up on beaches will concentrate on the high tide line. After some time, when several tides have passed, the plastics will become more dispersed or they will end up higher up on the beach during a spring tide situation. The latter happened on Schiermonnikoog in 2019, when many plastic pellets ended up in the line of dunes, where they were cleared away. Normally, however, the clean-up of washed-up pellets on beaches will focus mainly on the area between the high and low tide lines.

Although at first glance a beach appears to contain little life, there are a number of smaller species that feel at home in and on the drying sand. Janssen et al. (2005 and 2008) identified a limited number of typical beach species that were found up to the high tide line of Dutch beaches. As most important species they mention the worm Scolelepis squamata, and three crustaceans, the sand hopper (Talitrus saltator), the sand digger shrimp (Bathyporeia pilosa) and the amphipod Haustorius arenarius.

The highest densities and species richness of benthic organisms, however, are found slightly deeper than at the average water level. This applies to both sandy beaches (Janssen et al., 2005) and more silty tidal areas (Beukema, 2002). On sandy beaches, the benthic community mainly consists of small worms and crustaceans and an occasional (juvenile) mollusc. All these species are adapted to periodic drying of their habitat and will then bury themselves in the sediment. The worms live mostly under the sediment surface anyway, while the crustaceans are more often found at the surface where they use washed up organic material (seaweed, dead animals) as food. Adult sand hoppers, for example, can burrow to a depth of $15 \mathrm{~cm}$ (Vader, 1969), while the amphipod $H$. arenarius can be found at depths up to $30 \mathrm{~cm}$.

These worms and crustaceans form food for birds that forage along the flood line, such as sanderlings (Calidris alba). However, it is assumed that these small benthic animals make up only a limited part $(<10 \%)$ of the birds' diet (Vanermen et al., 2009), and that the birds mainly feed on easier to obtain and larger food items such as washed-up dead shellfish or crustaceans.

Tourist beaches are regularly cleaned using beach cleaners (see section 3.5), mainly removing larger waste and washed-up seaweed. Several studies have shown a negative effect of these cleaning actions on benthic life. Negative effects have been shown on bottom-dwelling animals that are 'run over' by vehicles (Schlacher et al., 2007). A probably greater effect is due to the removal of washed-up natural material that forms the food for small crustaceans in particular (Llewellyn \& Shackley, 1996; Zelinski et al., 2019). In addition to reducing the food supply, beach clearing also removes animals from the beach that are present in/on the washed-up seaweed. On beaches that are regularly 'cleaned', this leads to a substantial reduction in the number of small crustaceans, such as sand hoppers. From an ecological perspective, it is therefore recommended to alternate cleaned and uncleaned areas on a beach and to move the cleared seaweed to the uncleaned areas (Zelinski et al., 2019).

To remove washed-up microplastics from beaches, use is made of scooping or vacuuming, motorised or otherwise. Scooping removes the top layer of sand. In a dynamic area such as a sandy beach, this superficial disturbance of the sediment will not have any adverse effects on the environment. Depending on which excavation depth is reached, more or fewer organisms will be included and directly affected or removed. These numbers will increase closer to the low tide line. During the sieving of the sand, some of these organisms will undoubtedly remain on the sieve and some will be damaged, which would result in lower densities of benthic organisms in the treated areas. The ecological impact of this is likely to be very limited when it concerns temporary clean-up operations and not regular 'maintenance' operations. The species, especially small worms and crustaceans, found on sandy beaches between the high and low tide lines are adapted to a dynamic environment and are therefore considered capable of responding quickly to dynamic conditions and recovering from minor 
disturbances. As a food source, they are of limited interest to birds that forage along the high tide line, while (juvenile) fish can also feed below the low tide line where no clearing has taken place because floating microplastics will not strand there. This deeper water forms the habitat of many of the species that are also found between the low and high tide lines, which will speed up the recovery of the community in the cleared area.

A number of beaches are home to birds that are considered of ecological importance, such as the Kentish plover (Charadrius alexandrinus), the little tern (Sterna albifrons) and the common ringed plover (Charadrius hiaticula). Clean-up operations at such locations therefore deserve extra attention. Here too, it is important to act quickly in order to clear away the plastics around the high tide line before they reach the higher areas where the birds nest.

\subsection{Tidal flats}

At some locations microplastics that are lost at sea can be deposited on tidal flats during low tide. These flats are characterised by a high biological production and a relatively high biodiversity, making them important foraging areas for birds and fish during low and high, tide respectively (see for example Christianen et al., 2015).

The often silt-rich flats are difficult to walk on by man and and particularly hard to reach with heavier equipment, which means that in most cases only manual clean-up methods can be applied. This will involve intensive access to the area. Most benthic organisms present on these flats can cope well with some physical disturbance of the sediment surface, but shellfish 'kicked' deep into the silt will not recover. Mussel beds can therefore be better spared, as recovery from the effects of treading may take several years.

As tidal flats are by definition located below the high tide line, floating plastic pellets deposited on them will most likely be carried away again during high tide. It is therefore unlikely that these plastics will accumulate here. Clearing microplastics from tidal flats therefore does not seem to be a logical first choice after an incident.

\subsection{Salt marshes}

Soon after an incident, floating microplastics on a salt marsh can be expected to spread over an area up to the high tide mark. However, most plastics are likely to be deposited at the high tide mark itself, as found in previous research by Viehman et al. (2011). Over time, however, the microplastics can be spread over a wider area between the low and maximum high tide line across the salt marsh, as is also the case on beaches. The same tidal movements also cause sediment to sink, under which microplastic particles will eventually be buried (Lloret et al., 2021).

The presence of plants makes it more difficult to clean up microplastics that wash ashore on the salt marshes. Mowing and removing the plant material between which the plastic is found, is an option but results in a lot of waste from which the plastic is then difficult to separate. This type of operation was attempted in 2019 on Schiermonnikoog along the row of dunes (Figure 10),

In addition, removing the vegetation has a negative impact on the development of the salt marsh. In order to remove the plastic effectively, the vegetation should be mowed as short as possible above the surface. As long as the bare patches have not been restored, less sedimentation will take place here, as there are no plants that reduce the water flow rate allowing sedimentation of clay or sand to take place (Peralta et al., 2008).

Instead of mowing the plants and removing plant material, a hoover can be used to remove as many microplastics as possible from between the plants. This will become more difficult with increasing density of the vegetation. When vacuuming, the substrate and plants remain untouched in principle, but loose material (the litter layer) is removed. Coarse plant material can be separated from the 
microplastics by sieving, but to our knowledge, at present, no suitable methods exist for separating microplastics from the fine fraction of the litter layer. Therefore, in current practice, at least the fine fraction of the vacuumed material is necessarily disposed of in a waste incineration plant.

As most of the plastic will be deposited in the flood mark, it is most effective to remove this freshly deposited litter layer. Especially in autumn, many seeds are present among this material, and various organisms can also be found there (Chang et al., 2016), such as the marsh snail (Myosotella myosotis), shore hoppers (Orchestia gammarellus) and larvae of several fly species, which live on the litter or on the microorganisms on the litter (Schrama et al., 2017). In addition, the litter, during decomposition, is also a source of nutrients (Schrama et al., 2015). Consistent removal of the litter layer can therefore affect the supply of seeds, and locally reduce the nutrient supply on the salt marsh.

However, when litter removal is only incidental, as in the case of a clean-up operation after an incident, it will not have direct adverse effects on the salt marsh. Moreover, if timely action is taken, the removal work can be limited to the area around the flood mark. The species which are removed with the litter are also present in litter elsewhere on the salt marsh. Therefore the removal of a relatively small part will probably not have a substantial effect on the population of those species.

Swift action is also advisable to prevent the plastics from being carried higher up on the salt marsh by wind and spring tides. Apart from the fact that the plastics are then spread over a larger surface area, the vegetation higher up on the salt marsh is denser and the litter layer thicker, making clean-up more difficult. Moreover, in the breeding season, this area is used by breeding birds. Therefore cleaning up in the breeding season should be avoided.

A longer delay in cleaning up will also result in a larger part of the microplastics becoming buried and therefore impossible to be removed without disturbing the soil. As long as the pellet quantities are not extreme, the damage caused by the presence of the pellets in the soil is unlikely to outweigh the damage caused by cleaning up.

Every clean-up operation involves at least intensive access to the site and possibly the use of vehicles. Access to the salt marsh will not be a major problem because most of the salt marshes in the Netherlands are already walked on quite intensively by the cows and horses that graze them. Incidental more intensive treading need not have any effect on the salt marsh, although the pioneer zone (on and near the mudflats) can be considered more vulnerable.
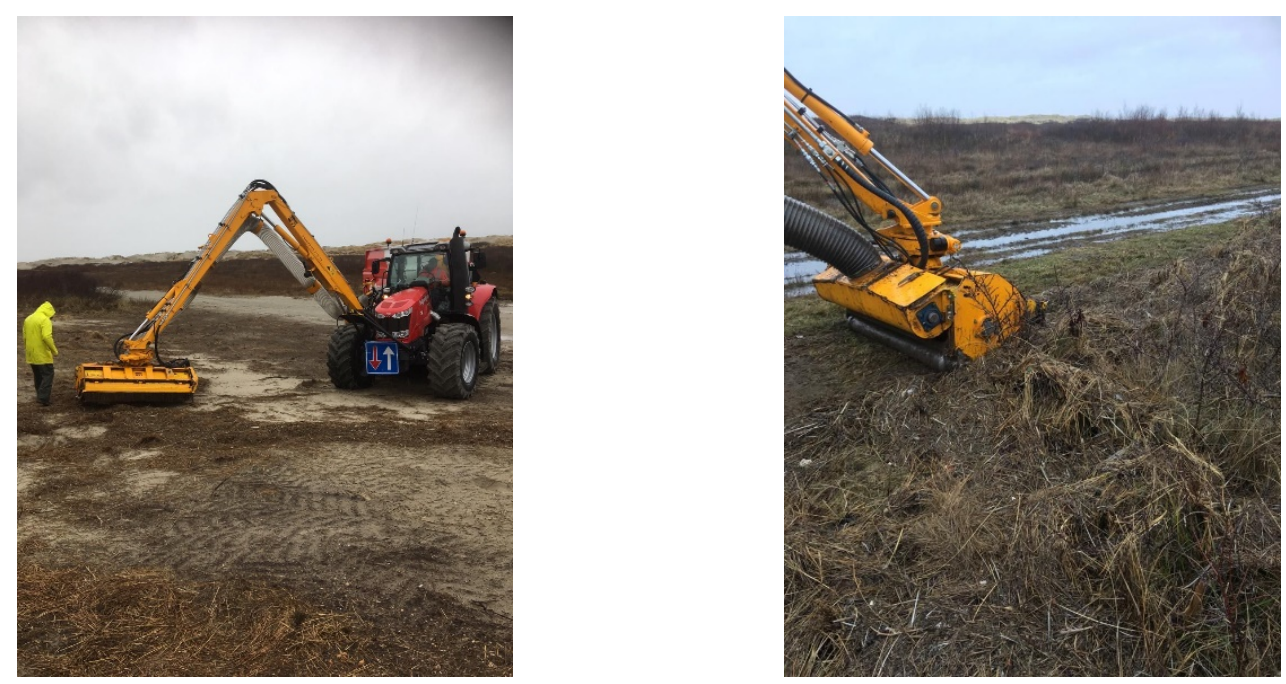

Figure 10 Deployment of the suction flail mower along the dune row on Schiermonnikoog (Photo credits: Jan Willem Zwart, Natuurmonumenten) 


\subsection{Solid dikes}

Basalt blocks or asphalt are mainly used to finish Dutch solid sea dikes around the water line. A poured layer of asphalt offers organisms little opportunities for adhesion or shelter. Cleaning up microplastics washed up above the low water line on such dikes therefore has no negative consequences for the local ecology. Moreover, the smooth surface of such dikes makes them easy and effective to clean with 'hoovers'.

Dikes made of basalt blocks or quarry stone have more places for organisms to settle, mainly below the low water line. On the section above, between the low and high tide lines, only organisms that can withstand periodic drying out during the low tide period will be able to settle. Barnacles, mussels, oysters, periwinkles and bladder wrack are the typical species to be expected here. These species are (able to ) firmly attach to the substrate to withstand the water currents during high tide, and will therefore not easily be removed when using a hoover to clean up plastics. The efficiency of using the hoover will be negatively affected by the presence of seaweed, mussels and oysters if the microplastics end up between and underneath them.

Also, it is often not possible to vacuum up the plastics that have sunk deep between the basalt blocks. One interviewee mentioned that a basalt dike can only be fully cleaned when the stones are picked up.

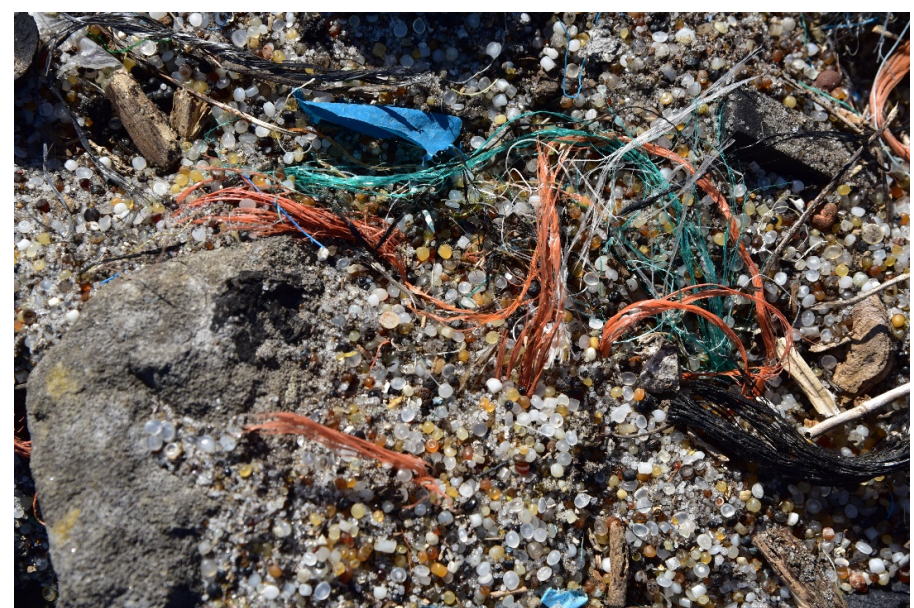

Figure $11 \quad$ Large quantities of microplastic can accumulate on some sections of dikes (here in the Port of Rotterdam) (Photo credits: HEBO maritiemservice BV). 


\section{Evaluation of clearing methods}

Table 1 provides an overview of the applicability of the various clean-up methods based on the data collected. There is little well-documented information available on the effectiveness of the methods under different conditions. So the table estimate should be considered indicative only. Field tests of the available methods under realistic conditions are necessary to obtain more reliable information.

The evaluation reveals an unambiguous picture of the clean-up methods after maritime incidents. Broadly speaking, there are three methods used to remove microplastics, namely raking, shovelling and vacuuming, followed by using a sieve or not to separate materials.

Scooping or raking are suitable methods for removing plastics from soft soils without vegetation, such as beaches and possibly tidal flats. On hard surfaces, and on moist sand, the hoover is an effective way to collect microplastics fairly selectively, especially if the pellets are still on top of the sand. Pellets which have been kicked or driven into the sand are difficult to vacuum up. If the sand is dry, a lot of sand will also be vacuumed up and a combination with a sieve system is recommended to separate pellets from sand. For the vacuuming method to work effectively, it is important to avoid vacuuming coarse (plant) material as this can quickly clog the vacuum hose.

Vacuum cleaning can also be used on overgrown areas, but the denser the overgrowth becomes, the less effective the collection of microplastics will be. Mowing and disposing of the vegetation and plastic is then a possibility, but this may have a substantial impact on the local ecosystem during the growing season.

The ecological impact of the other clean-up methods is estimated to be minimal, especially if the duration of the clean-up activities and the size of the area to be cleared can be limited by rapid intervention.

The clearing methods can be applied both manual and motorised. Manual raking, shovelling or sieving is mainly used by volunteers to clean up microplastics at known hotspots and thus generate public attention for the chronic microplastic contamination. Manual methods can also be practical for cleaning up microplastics in areas where the use of heavy motorised equipment is not possible or desirable. Obviously, the area that can be cleaned up manually by one person is limited. Professional motorised systems are more suitable for cleaning up larger, easily accessible areas. On dry sand, beach cleaners with finer sieves than those traditionally used, could possibly be used. On all other surfaces, the hoover method seems to be the most effective.

Depending on the locations where work is being done, more or less other material will also be unintentionally collected, together with the microplastics, such as larger litter, sand, shells and plant material. The use of sieves works well to separate plastic pellets from dry sand, or dry coarse material such as shells or plant material. When the collected material is moist and therefore clumps together, sieving becomes more difficult. This can probably be solved by using water during the sieving process, but to our knowledge this has not yet been applied in practice on location in the Netherlands. As far as we know, no suitable method has yet been developed for separating microplastics from plant material of the same size. In practice, this fraction of the collected material will be disposed of as a whole. The amount of larger litter that is unintentionaly collected depends on the method. With manual methods, larger pieces can be collected manually after being traced by eye. If hoovers are used, the diameter of the suction mouth determines the maximum size of the litter that can be collected. In practice, however, coarse material is avoided as much as possible because it can quickly clog the suction hose. Beach cleaners are designed to remove coarse litter as well as seaweed from beaches. By using finer sieves, it would theoretically be possible to remove this coarse material along with the microplastics. Whether this works in practice will have to be investigated. It should be noted that it will also be difficult to mechanically separate plastics from plant material such as seaweed. 
Table $1 \quad$ Indicative classification of the clean-up methods based on the information obtained from literature, interviews and the Internet. $++=$ suitable; $+=$ fairly $/$ possibly suitable; - = unsuitable. Development stage $1=$ not yet tested; $2=$ prototype tested; $3=$ commercially available; ? = no information available; n.a. = not applicable, method is not suitable for this application.

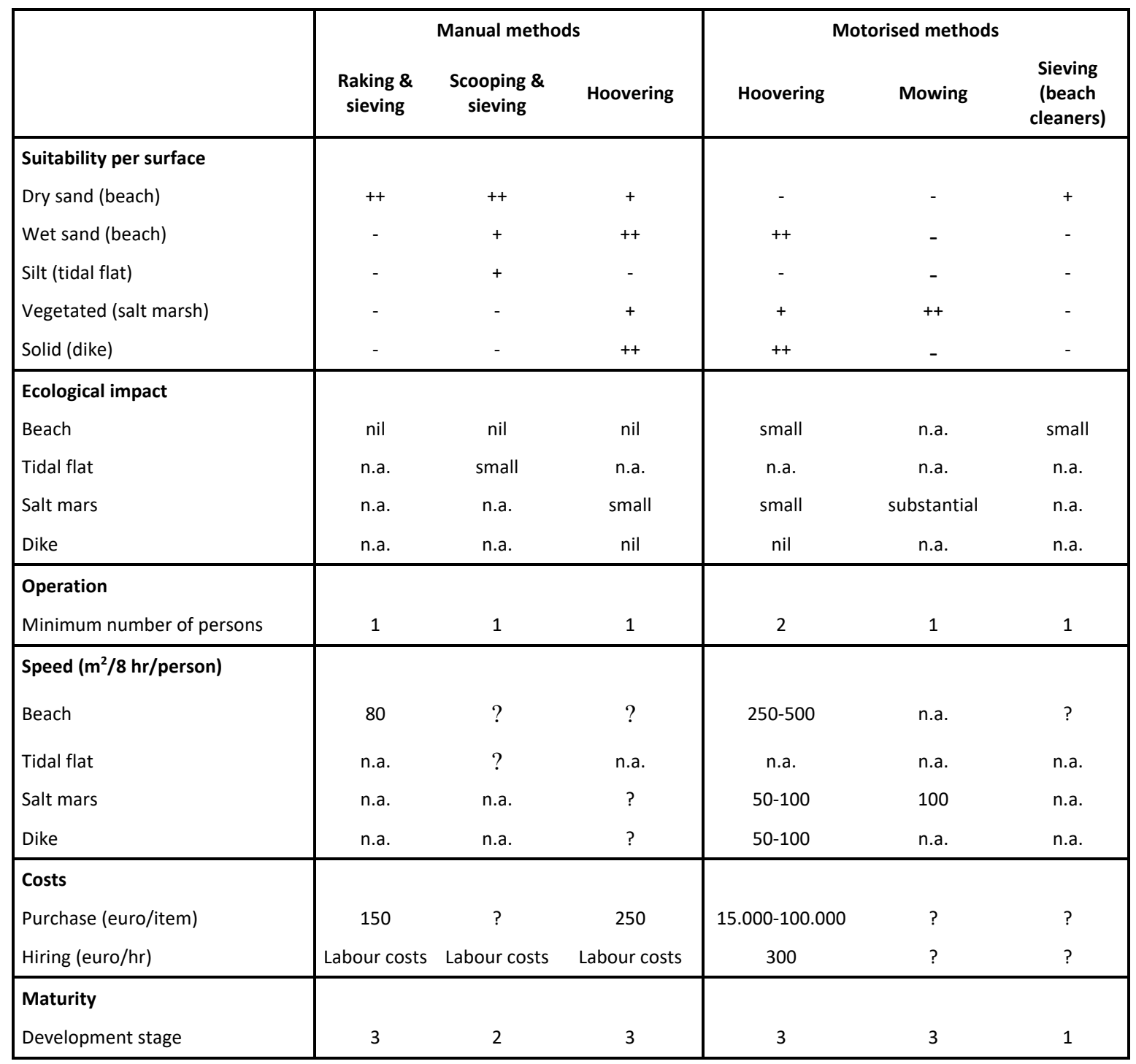




\section{Clearing of plastics from water}

The previous chapters dealt with the clean-up of microplastics washed up on land. In some situations, it may be possible to start cleaning up earlier; while the plastics are still on the water. In the case of an oil spill, this is the preferred strategy because stranded oil causes a lot of inconvenience and is difficult to clean up. At various locations in the Netherlands equipment is stored that can be used to clean up floating oil and prevent it from spreading. These oil skimmers and oil containment booms may also be used in response to a concentrated discharge of floating microplastics. During oil spill response exercises, this equipment proved effective in retaining and removing floating popcorn that was used to simulate an oil slick (personal comment Jean Groels, RWS).

An important precondition for this approach is that the plastics floating on the sea are detected before they are spread over a large surface. This detection will be more difficult for microplastics than for oil, for which a stain is often clearly visible from the air.

It may be possible to use oil containment booms as barriers to protect vulnerable areas that are difficult to clean from floating microplastics. This could be done preventatively if, based on wind and current, it can be assumed that lost microplastics will reach these areas. Placing the barriers could also prevent further contamination of an area where the first plastics have washed ashore shortly after the incident. Oil booms are stored at a number of strategic locations along the Dutch coast, such as Harlingen and Rotterdam. They have a length of approximately $200 \mathrm{~m}$ and are interconnectable. Because of their height of 1 to 2 metres, they also work with a certain wave action. 


\section{$7 \quad$ Conclusions and recommendations}

\subsection{Most effective cleaning technique}

Vacuum cleaning seems to be the most suitable method for cleaning up washed-up microplastics from different surfaces. On sand, however, it is important that the plastic granules are still on the surface and have not been pushed into it by treading. On overgrown terrain and non-asphalted dykes, the cleaning efficiency will be lower than on flat, damp beaches or asphalted dykes. Depending on the subsoil, more or less other material, such as sand and plant residues, is vacuumed up together with the microplastics.

Size fractions can be separated using sieves. Within the fraction containing the most microplastics, further separation could be achieved by using differences in buoyancy. Further large-scale separation of microplastics and plant residues within a size fraction is not possible at present. Separating the material as much as possible during clean-up has the advantage that less waste needs to be stored/disposed of and that natural material can be left behind in the area. However, if this separation can only take place at another location, the added value is probably low.

\subsection{Ecological impact of cleaning}

Ecological effects of pellets are unclear and possibly too subtle to be observed under field conditions, but for ethical and aesthetic reasons alone, lost waste should always be cleaned up as much as possible.

It is inevitable that organisms will be damaged or removed during clean-up operations. However, when these take place in a limited area, rapid recovery from surrounding terrain is possible. Especially when the structure of the subsurface is not changed by the clean-up operations. This will not be the case on hard surfaces and sandy beaches, but on salt marshes, for example, it is wise not to mow rigorously in order to remove the last pellets.

Recovery will only start after the clean-up activities have ceased, which is why it is important to choose a strategy after an incident that limits the time span as well as the surface of the area to be cleaned as much as possible (see 7.3).

Fortunately, maritime incidents, where microplastics are lost, do not occur regularly in the same area, requiring clean-up operations to be carried out incidentally and giving the ecosystem time to recover.

\subsection{Response and Cleaning strategy}

It is important to act quickly after a maritime incident involving a large release of plastic microplastics. For various reasons, cleaning up washed-up microplastics becomes more difficult as time passes, and the ecological impact will also increase. The plastic is initially deposited on the tide mark and will in time be dispersed over a larger area driven by tidal movements and wind. Plastics that are not cleared away quickly will become buried under drifting sand on beaches, and will be pushed into the sand by walkers and vehicles, which reduces the efficiency of using a hoover.

After some time, plastics deposited on a salt marsh can also reach the higher areas, where the denser vegetation makes clearing more difficult. The higher areas on a salt marsh, and to a lesser extent on beaches, are also used by nesting birds. Therefore clean-up operations during the breeding season are not recommended.

The best clean-up strategy therefore seems to be to start clearing the tide mark as soon as possible after the incident, and to do this preferably after each high tide period. Beaches could be screened off 
for walkers and beachcombers to prevent the plastics being pushed into the sand. In the event of an incident off the coast, it will not take weeks for the largest amount of microplastics to be washed ashore. Dispersal models, for example, estimated that after the MSC Zoe incident, most of the pellets had washed ashore somewhere within 3 weeks (Foekema et al., 2021).

During this 'washing-up period', in addition to regular cleaning of the high tide line, efforts can also be made to protect areas such as salt marshes that are difficult to clean up, from plastic drift. For example by using oil containment booms.

To enable the ideal fast response, it is necessary that clearing equipment is available on stand-by in the country and can be quickly transported to the right place for operation.

\subsection{Cooperation}

While performing this inventory, it was noticed that there is little cooperation on the clean-up of microplastics, and that each incident is more or less dealt with locally. As a result, the same techniques are being invented in different places, and the same bottlenecks are being identified. Even within the Netherlands, there appears to be little communication between the professional parties involved in the clean-up of microplastics. For none of these parties microplastic clean-ups is core business and further development of potentially more efficient methods does not take place since the market potential seems limited.

The exchange of knowledge and experience in the field of microplastics disposal and removal could be promoted within the Netherlands, and preferably within Europe or even on a global scale. If different prototypes can be tested in this context, a better picture of the actual effectiveness will also be obtained. Rijkswaterstaat could consider organising such cooperation, certainly if it can also offer some market perspective to the various parties.

\subsection{Knowledge gaps}

The indications in this inventory of the effectiveness of the various clearing methods on different surfaces are based on statements by the builders and users of the systems and sometimes on observations by third parties. Specific tests are required for an objective assessment.

Separating microplastics from plant material of the same size in particular is not yet possible effectively. Developers indicate that they do have ideas on how this could be done, but are reluctant to share these at this stage. As a result, it also remains unclear how effective such ideas will be in practice.

Densely vegetated salt marshes and silty tidal flats are difficult to clean without substantial impact on the local system. Ideally, pollution of these areas should be prevented by collecting the plastics from the water at an early stage. This could be done by deploying oil containment booms. However, (floating) microplastics are difficult to locate at sea. It may be possible to develop an airborne localisation technique that would make it easier to clean up at sea, certainly in combination with particle distribution models that predict the locations where most microplastics are likely to strand.

If microplastics do end up in salt marshes and on muddy tidal flats, 'doing nothing' may be the best option, as the impact of the presence of plastic pellets on the ecosystem seems small. However, without specific research, this remains an assumption. Longer-term research into the effects of plastic pellets on such areas and on the related part of the ecosystem (foraging birds) to test this assumption would be useful. 


\section{Acknowledgements}

A significant part of the information described in this report was obtained through interviews with the following persons: Henk Middendorp and Jean Groels (both RWS), Anna Wegner (Waterschap Rijn en IJssel), Ivo Pallemans and Tom van Vooren (both Envisan), Stefan van 't Land (HEBO), Andre Borsch (DBS Harlingen), Josh Beech (Nurdle.org), Eric de Vries (Bende van Strand), Jan Willem Zwart (Natuurmonumenten). We thank them for unselfishly sharing their information, insights, thoughts and opinions. Rune Bergstrøm (Norwegian Coastal Administration) and Anne-Sophie Lapointe (HoolaOne) provided valuable information via email. 


\section{References}

Boitsov, S., Knutsen, H., Simonsen, J.H., Frantzen, S., 2020. Undersøkelse av mageinnhold i fiskeyngel og kystnære fiskearter etter utslippet av plastpellets fra M/V Trans Carrier - Studies of stomach contents in juvenile and coastal fish species after discharge of plastic pellets from M/V Trans Carrier. Havforskningsinstituttet, Bergen, Norway, pp 17

Carpenter, E.J., Anderson, S.J., Harvey, G.R., Miklas, H.P., Peck, B.B., 1972. Polystyrene Spherules in Coastal Waters. Science 178: 749-750 doi http://dx.doi.org/10.1126/science.178.4062.749

Chang, A.E.R., Veeneklaas R.M., Bakker J.P., 2016. Seed Dynamics Linked to Variability in Movement of Tidal Water Stable URL : http://www.jstor.org/stable/4499221

Christianen M.J.A., Holthuijsen S.J., van der Zee E.M., van der Eijk A., Govers L.L., van der Heide T., de Paoli H., Olff H., 2015. Ecotopen- en Kansrijkdomkaart van de Nederlandse Waddenzee. Waddensleutels rapportnummer 2015.04.01. DOI: 10.13140/RG.2.1.4145.4243

Day, R.H., 1980. The occurrence and characteristics of plastic pollution in Alaska's marine birds. Master thesis. University of Alaska, Fairbanks, pp 120

de Carvalho-Souza, G.F., Llope, M., Tinôco, M.S., Medeiros, D.V., Maia-Nogueira, R., Sampaio, C.L.S., 2018. Marine litter disrupts ecological processes in reef systems. Marine Pollution Bulletin 133: 464-471 doi https://doi.org/10.1016/j.marpolbul.2018.05.049

Dolva, H., Solem Holt, H., Henriksen, T., Nordaas, S., 2020. Erfaringer fra plastpelletsaksjonen Trans Carrier, med fokus på rensemetoder på strand - Experiences from the plastic pellets pollution incident from Trans Carrier, with focus on shoreline clean-up operations. Kustverket - Norwegian Coastal Administration, Ålesund, Norway, pp 36

Ebbesmeyer, C.C., Ingraham, J., W. James, 1992. Shoe spill in the North Pacific. Eos, Transactions American Geophysical Union 73: 361-365 doi https://doi.org/10.1029/91EO10273

Ebbesmeyer, C.C., Ingraham, W.J., Royer, T.C., Grosch, C.E., 2007. Tub toys orbit the Pacific subarctic gyre. Eos, Transactions American Geophysical Union 88: 1-4

Foekema, E., van der Molen, J., Asjes, A., Bijleveld, A., Brasseur, S., Camphuysen, K., van Franeker, J.A., Holthuijsen, S., Kentie, R., Kühn, S., Leopold, M., Kleine Schaars, L., Lok, T., Niemann, H., Schop, J., 2021. Ecologische effecten van het ongeluk met de MSC Zoe op het Nederlandse Waddengebied, met focus op microplastics. NIOZ Rapport 2021-03. NIOZ Royal Netherlands Institute for Sea Research, 't Horntje, Texel, The Netherlands. 99pp. DOI: 10.25850/nioz/7b.b.mb

Foekema, E., Kühn, S., Elschot K., Van Puijenbroek, M., 2021a. Inventarisatie aspecten rondom opruimen microplastics na maritieme incidenten. Wageningen University \& Research rapport 095/21. https://doi.org/10.18174/558084

Galafassi, S., Nizzetto, L., Volta, P., 2019. Plastic sources: A survey across scientific and grey literature for their inventory and relative contribution to microplastics pollution in natural environments, with an emphasis on surface water. Science of The Total Environment 693: 133499 doi https://doi.org/10.1016/j.scitotenv.2019.07.305

Harper, P.C., Fowler, J.A., 1987. Plastic pellets in New Zealand Storm-killed Prions. Notornis 34: 65-70

Haseler, M., Schernewski, G., Balciunas, A., Sabaliauskaite, V., 2018. Monitoring methods for large microand meso-litter and applications at Baltic beaches. Journal of Coastal Conservation 22: 27-50 doi https://doi.org/10.1007/s11852-017-0497-5

Haseler, M., Weder, C., Buschbeck, L., Wesnigk, S., Schernewski, G., 2019. Cost-effective monitoring of large micro- and meso-litter in tidal and flood accumulation zones at south-western Baltic Sea beaches. Marine Pollution Bulletin 149: 110544 doi https://doi.org/10.1016/j.marpolbul.2019.110544

Haseler, M., Balciunas, A., Hauk, R., Sabaliauskaite, V., Chubarenko, I., Ershova, A., Schernewski, G., 2020. Marine Litter Pollution in Baltic Sea Beaches - Application of the Sand Rake Method. Frontiers in Environmental Science 8 doi https://doi.org/10.3389/fenvs.2020.599978

Janssen G. \& Mulder S., 2005. Zonation of macrofauna across sandy beaches and surf zones along the Dutch coast. OCEANOLOGIA, 47 (2), 2005. pp. 1-18

Janssen G., Kleef H., Mulder S. \& Tydeman P., 2008. Pilot assessment of depth related distribution of macrofauna in surf zone along Dutch coast and its implications for coastal management. Marine Ecology 29 (Suppl. 1) (2008) 186-194 
Koelmans, A.A., Besseling, E., Wegner, A., Foekema, E.M., 2013a. Plastic as a Carrier of POPs to Aquatic Organisms: A Model Analysis. Environmental Science \& Technology 47, 7812-7820

Koelmans, A.A., Besseling, E., Wegner, A., Foekema, E.M., 2013b. Plastic As a Carrier of POPs to Aquatic Organisms: A Model Analysis (vol 47, pg 7812, 2013). Environmental Science \& Technology 47, 89928993

Peralta, G., van Duren L., Morris, E., Bouma, T. 2008. Consequences of shoot density and stiffness for ecosystem engineering by benthic macrophytes in flow dominated areas: a hydrodynamic flume study. Marine Ecology Progress Series 368:103-115

Kartar, S., Abou-Seedo, F., Sainsbury, M., 1976. Polystyrene waste in the Seventh Estuary: A progress report. Marine Pollution Bulletin 4: 144 doi https://doi.org/10.1016/0025-326X(76)90092-8

Kühn, S., Van Franeker, J.A., 2020. Quantitative overview of marine debris ingested by marine megafauna. Marine Pollution Bulletin 151: 110858 doi https://doi.org/10.1016/j.marpolbul.2019.110858

Kühn, S., Meijboom, A., Bittner, O., Van Franeker, J.A., 2021. Fulmar Litter Threshold Value Monitoring in the Netherlands - Update 2020. Wageningen Marine Research, Den Helder, The Netherlands, pp 64 doi https://doi.org/10.18174/553736

Llewellyn, P.J., Shackley, S.E., 1996. The effects of mechanical beachcleaning on invertabrate populations. British wildlife 7: 147-155

Lloret, J., Pedrosa-Pamies R., Vandal N., Rorty R., Ritchie M., McGuire C., Chenoweth K., Valiela I., 2021. Salt marsh sediments act as sinks for microplastics and reveal effects of current and historical land use changes. Environmental Advances 4:100060

Mouat, J., Lozano, R.L., Bateson, H., 2010. Economic Impacts of Marine Litter. KIMO International, pp. 105

Ogi, H., 1990. Ingestion of plastic particles by sooty and short-tailed shearwaters in the North Pacific. Shomura R.S., Godfrey M.L., Proceedings of the Second International Conference on marine debris, Honolulu, Hawaii, pp 635-652

Philippart, K., Hanssen, L., van Dijk, J., 2019. Wat zijn de gevolgen van de door de MSC Zoe verloren lading voor de Noordzeekustzone en de Waddenzee? Onderzoeks- en monitoringplan voor de korte- en langetermijngevolgen van microplastics voor het Waddengebied en haar bewoners. Waddenacademie, Leeuwarden, The Netherlands

PlasticsEurope, 2020. Plastics - the Facts 2020. An analysis of European latest plastics production, demand and waste data. PlasticsEurope - Association of Plastics Manufacturers, Brussels, Belgium, pp 64 doi https://www. plasticseurope.org/en/resources/publications/4312-plastics-facts-2020

Rijkswaterstaat, 2021. https://www.rijkswaterstaat.nl/nieuws/archief/2021/01/overeenstemmingschadeafhandeling-met-reder-msc-zoe. Bezocht 26112021.

Ryan, P.G., 1988. Effects of ingested plastic on seabird feeding: evidence from chickens. Marine Pollution Bulletin 19: 125-128 doi https://doi.org/10.1016/0025-326X(88)90708-4

Schlacher, T.A., Thompson, L., Price, S., 2007. Vehicles versus conservation of invertebrates on sandy beaches: mortalities inflicted by offroad vehicles on gost crabs. Marine Ecology 28: 354-367

Schrama, M., van Boheemen L.A., Olff H., Berg M.P., 2015. How the litter-feeding bioturbator Orchestia gammarellus promotes late-successional saltmarsh vegetation. Journal of Ecology 103:915-924

Schrama, M., van der Plas F., Berg M.P., Olff, H. 2017. Decoupled diversity dynamics in green and brown webs during primary succession in a saltmarsh. Journal of Animal Ecology 86:158-169.

Tanaka, K., Yamashita, R., Takada, H., 2018. Transfer of Hazardous Chemicals from Ingested Plastics to Higher-Trophic-Level Organisms. The Handbook of Environmental Chemistry Springer, Berlin, Heidelberg. doi https://doi.org/10.1007/698_2018_255

Tanaka, K., Watanuki, Y., Takada, H., Ishizuka, M., Yamashita, R., Kazama, M., Hiki, N., Kashiwada, F., Mizukawa, K., Mizukawa, H., Hyrenbach, D., Hester, M., Ikenaka, Y., Nakayama, S.M.M., 2020. In vivo Accumulation of Plastic-Derived Chemicals into Seabird Tissues. Current Biology 30: 723-728 doi http://dx.doi.org/10.1016/j.cub.2019.12.037

Turner, A., Williams, T., Pitchford, T., 2021. Transport, weathering and pollution of plastic from container losses at sea: Observations from a spillage of inkjet cartridges in the North Atlantic Ocean. Environmental Pollution 284: 117131 doi https://doi.org/10.1016/j.envpol.2021.117131

UNEP, 2011. UNEP Year Book, 2011. Emerging issues in our global environment, United Nations Environmental programme, Nairobi, pp 79pp

Vader W., 1969. Verspreiding en biologie van haustorius arenarius, de zandvlokreeft, in Nederland (crustacea, amphipoda). Mededeling nr. 65 van het Delta Instituut voor Hydrobiologisch Onderzoek, Yerseke

Van Franeker, J.A., 1983. Plastics - een bedreiging voor zeevogels. Nieuwsbrief NSO 14: 41-61 
Van Franeker J. A., Bravo Rebolledo E. L., Hesse E., IJsseldijk L. L., Kühn S., Leopold M., Mielke L. 2018. Plastic ingestion by harbour porpoises Phocoena phocoena in the Netherlands: Establishing a standardised method. Ambio. 2018 May;47(4):387-397. doi: 10.1007/s13280-017-1002-y.

Vanermen N., Stienen E.W.M., De Meulenaer B., Van Ginderdeuren K. \& Degraer S., 2009. Low dietary importance of polychaetes in opportunistic feeding Sanderlings Calidris alba on Belgian beaches. Ardea 97: 81-87

Viehman, S., Vander Pluym J.L., Schellinger, J. 2011. Characterization of marine debris in North Carolina salt marshes. Marine Pollution Bulletin 62:2771-2779.

WSC, 2020. Containers Lost at Sea - 2020 Update. World Shipping Council (WSC), Washington, DC, USA, pp 4. https://safety4sea.com/wp-content/uploads/2020/2007/WSC-Containers-Lost-at-Sea2020_2007.pdf

Zelinski, S., Botero C.M., Yanes, A. 2019. To clean or not to clean? A critical review of beach cleaning methods and impacts Marine Pollution Bulletin, Volume 139, Pages 390-401.

https://doi.org/10.1016/j.marpolbul.2018.12.027 


\section{Justification}

Report C095/21B

Project Number: 4315100181

The scientific quality of this report has been peer reviewed by a colleague scientist and a member of the Management Team of Wageningen Marine Research

Approved: $\quad$ Dr. Ruud Jongbloed

Senior researcher

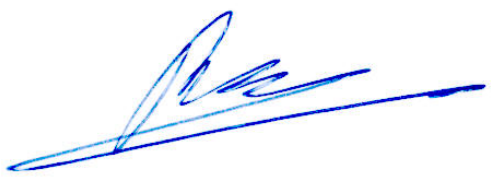

Date:

20 December 2021

Approved:

Drs. Jakob Asjes

Manager Integration

Signature:

Date:

20 December 2021 
Wageningen Marine Research

$\mathrm{T}+31(0) 317487000$

E: marine-research@wur.nl www.wur.eu/marine-research

Visitors' address

- Ankerpark 271781 AG Den Helder

- Korringaweg 7, 4401 NT Yerseke

- Haringkade 1, 1976 CP IJmuiden
With knowledge, independent scientific research and advice, Wageningen Marine Research substantially contributes to more sustainable and more careful management, use and protection of natural riches in marine, coastal and freshwater areas.

Wageningen Marine Research is part of Wageningen University \& Research. Wageningen University \& Research is the collaboration between Wageningen University and the Wageningen Research Foundation and its mission is: 'To explore the potential for improving the quality of life' 